\begin{tabular}{ccc}
\hline & International Journal of Engineering \&Technology, $7(1.7)(2018) 62-64$ \\
SPC & International Journal of Engineering \& Technology \\
Website www.sciencepubco.com/index.php/IJET & Research paper \\
\hline
\end{tabular}

\title{
Online e-tollgate fee collection using QRcode
}

\author{
Kuna Venkateswararao $^{1 *}$, L. Gurusarathy ${ }^{1}$, Akepati Sankar Reddy ${ }^{2}$ \\ ${ }^{1}$ Assistant Professor, Department of Computer Science and Engineering, School of Computing, Vel Tech Rangarajan \\ Dr. Sagunthala R\&D Institute of Science and Technology, Avadi, Chennai-62, TamilNadu, India \\ ${ }^{2}$ Annamacharya Institute of Technology and Science \\ *Corresponding author E-mail: kvrvenkateshkvr@gmail.com
}

\begin{abstract}
Now a day's People need to wait near the tollgate in queue for long time to pay the toll fee. The application on java is being introduced. Before we are reaching the tollgate it should display a message to the user that he is approaching the tollgate. The display of message based on GPS location. This Application helps to pay amount before the tollgate reached. Automatically it will generate an Electronic receipt with Barcode and QRcode in secure techniques .which can be shown at the tollbooth. This reduces the work of the people and the reduces the time. Payment is done through Mobile wallets or Credit cards. A list for all the tollgate and respective services to be made available in the application.
\end{abstract}

\section{Keywords: GPS; Barcode; Security; QRcode.}

\section{Introduction}

\subsection{Exiting tollgate system}

Tollgate is a gate on road at which you pay for an amount of money in order to allow using the road for vehicles. To pay tollgate free for any vehicle you need wait some time due to the gradually increasing number of vehicles. At payment time you said your vehicle number and type, then give to amount to tollgate. Every day, millions of mankind use to their own personal vehicles in place of public travel systems. This leads to steady increase in vehicle congestion in developing countries and toll payment system. Today's tollgate system needs the vehicle to stop at a toll plaza and collect toll fee is manually paid bill receipts. It is a slow work as manual colleting often leads to delay and mankind's have to wait .Progress in the traditional system is the ETC (Electronic Toll Collection System), which needs mankind's to have to use ETOLLGATE payment online web application.

\subsection{Objectives}

The main objective is to Online Toll Payment:

1) To Use online toll payment before reach the tollgate for controlling heavy traffic

2) To provide an effective less waiting time for traffic in Congested cities

3) Controls traffic to a maximum extent

4) Ensure traffic congestion totally based on the density of traffic

5) Represent Barcode used for verification of payment of tollgate

6) Use GPRS Technology for knowing nearest tollgates.

7) To provide happy journey to the travellers.

\subsection{Need for the study}

- Non Violation of rules

- Time Saving

- To eradicate traffic congestion during peak hours

- To avoid standby of traffic for a kilometer during peak hours.

- To enjoy safe and quick journey.

\subsection{Expected outcomes}

The main objective behind this proposal is to create a suitable ETC system to be implemented e-payment before reached to the tollgate. In this system first mankind register in to online application than login the application and add type of which it have and add payment type like card ,wallet etc. After successfully add the steps while nearest to the tollgate click on tollgate button it will show your near toll gate than select the tollgate and pay fee of vehicle charge based on criteria. After Success full payment it will generate a electronic barcode recipient than the recipient show to the tollgate crossing they will verify the payment using scanner. 


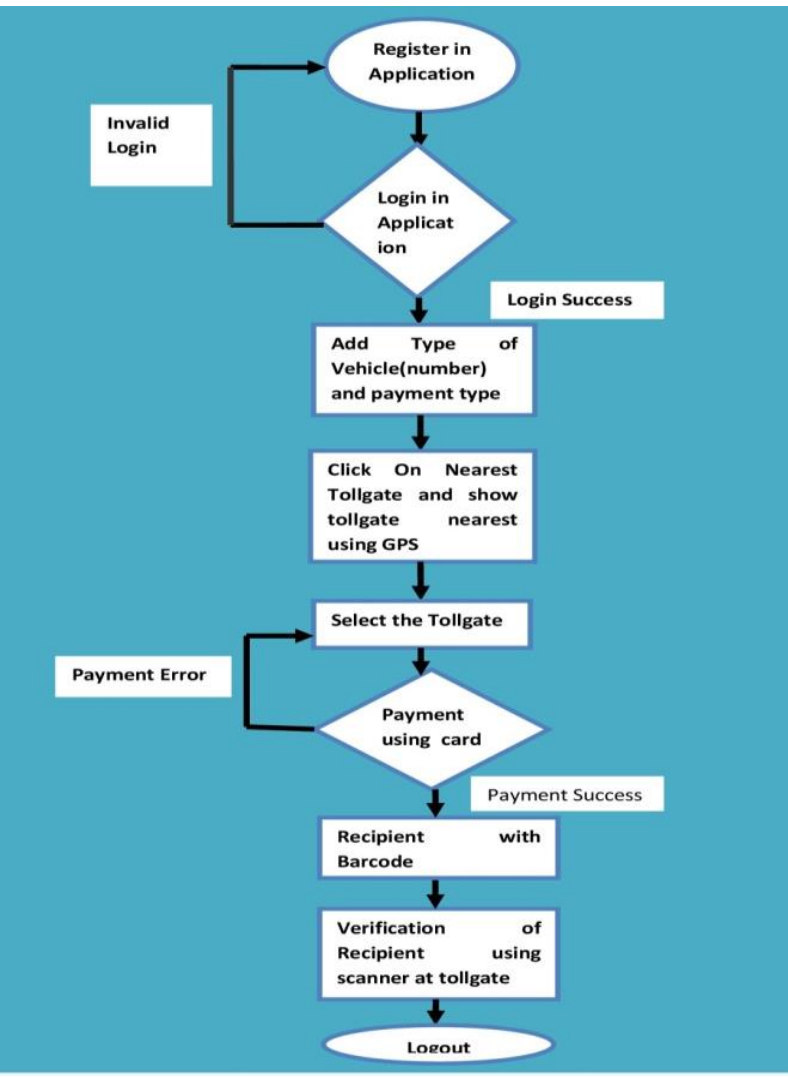

Fig. 1: Process of E-Toll Payment.

In this process to fine nearest tollgate using GPRS technology for finding nearest tollgate and payment Mode is secured with gateway encryption mechanism. The generate payment receipt with barcode .barcode represents the particular toll gate details and payment verification. Tollgate payment verification person use barcode scanner to verify the details of payment and vehicle.

The implemented model makes sure that traffic at the toll gates is streamlined and security is also present. The fee which is claim is based on the load carried by the vehicle. This system we can also identify all vehicles. Through online payment no need to wait more time and it gives the exact free to tollgate.

Advantages:

- Time save

- Reduce the traffic

- Less Waiting time

- Secure Payment

- Exact payment

\section{Related work}

QR (Quick Response Code) is the trade mark for a kind of matrix barcode (or Two -dimensional barcode) first designed for the self motorized industry in Japan. A barcode is a machine-readable Optical label that contains in format ion about the item to which it is attached. A QR code uses four standardized Encoding modes to efficiently store data. The QR code is a matrix consisting of an array of nominally square modules arranged in an overall square pattern, including a unique pattern located at three corners of the symbol and intended to assist in easy location of its position, Size and inclination. QR Code Generation is encrypted string is converted to a $\mathrm{QR}$ image using an algorithm. QR code algorithm is made up of two different stages. The first one is similarity transformation where the novel matrix gets transformed in limited steps to real tridiagonal or Hessenberg form. The first stage of the QR algorithm prepares for the next stage which is the actual iterations of tridiagonal or Hessenberg matrix form. Through this QR code generates the payment of code, then secure transformation amount from mankind to tollgate authority [1].
The toll gate process using electronic technology allows the electronic collection of toll payments. This technology has been studied by researchers and enforced in various highway areas, bridges, and tunnels involving such a process. This process is capable of determines if the car is registered or not, and then inform to transport authorities of toll payment violations, debits etc. The most obvious assert of this topology is the opportunity to oust congestion in tollgates, especially during holidays time when travel tends to be heavier than normal. It is also a model by which to different complaints from mankind's regarding the inconveniences involved in manual process payments at the tollgates. Other than this obvious advantage is that it could also benefit the toll operators. Online installment portals make charge card transactions significantly more productive, easy and suitable with cluster transfer characteristics to submit different transactions in a solitary record and the capability to check accounts rapidly and safely. The advantages for the driver through this model can be reduce line at toll gates, faster and more efficient service (no exchanging toll fees by manual), the able to make payments by keeping a balance on the their card or by loading a registered credit card.[2]

Global Positioning System (GPS) technology is changing the way we work and play different roles. You can use GPS technology when you are driving, flying, fishing, sailing, hiking, running, biking, working, or exploring. With a GPS receiver, you have an amazing amount of information at your hands. Here are just a few examples of how you can use GPS technology.GPS technology requires three segments space segment, control segment, user segment. Space segment provide space for using satellite in orbit. The control segment constantly monitors the GPS constellation and uploads information to satellites to provide maximum user accuracy. The GPS user segment consists of your GPS receiver. Particular your receiver collects and processes signals from the GPS satellites that are in view and then uses that information to determine and display your location, speed, time, and so forth. Your GPS receiver does not transmit any information back to the satellites. Your GPS receiver collects information from the GPS satellites that are in view. Your GPS receiver determines your exact location, velocity, and time. It can calculate other information, such as bearing, track, trip distance, and distance to destination, sunrise and sunset time so forth. GPRS (general packet radio service) is a packet - based data bearer service for wireless communication services that is delivered as a network overlay for GSM, CDMA and TDMA networks. [7]

\section{Methodology}

\subsection{Technologies}

To design application using client server architecture. In this architecture client at as our application and server is tollgate payment gateway.

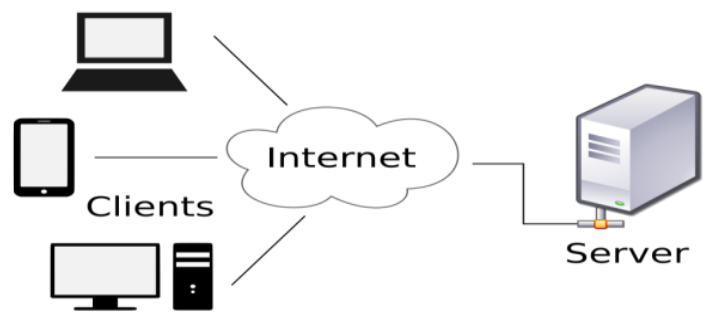

Fig. 2: Client-Server Architecture.

To design front end using HTML and CSS and back end technologies is Jdbc, Servlets, and JavaServerPagers. HTML stands for Hyper Text Markup language. It describes the structure of webpage's and represents tages.CasCading Style Sheet describe the how the html elements are displayed and style of html document. Payment of tollgate integrated with HAI database for pay vehicle toll free. Database connectivity using JDBC technique. 
Servlet is server side language and it will run on the server side. It acts as interface between the client and server. Client act as a browser and server is the database. JDBC is used for database connectivity and design application logic, manipulations. Bootstrap is used to design affective user interface design and attractive of users.

QR Code stands for Quick Response Code. It is used to take a piece of information from a transitory media and put it in to your cell phone. After success full payment of particular toll gate then QRCODE is generated using online open source software. While reached to tollgate, person will verify the payment through $Q R$ scanner if it is valid you crass the tollgate otherwise repayment. Global Positioning System (GPS) technology is used to find the location of the mankind area, search nearest tollgate and select payment of tollgate .In this process to reduce the waiting time for payment at tollgate and reduce traffic and secure payment.

\section{Results}

First user register using their credential then login, after login successfully add type of vehicle and payment type.

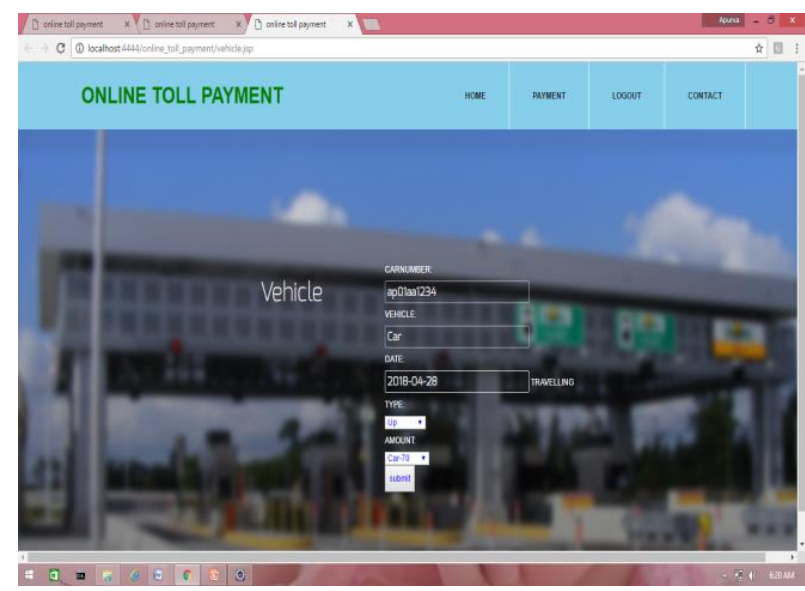

Fig. 4: Select Type of Vehicle.

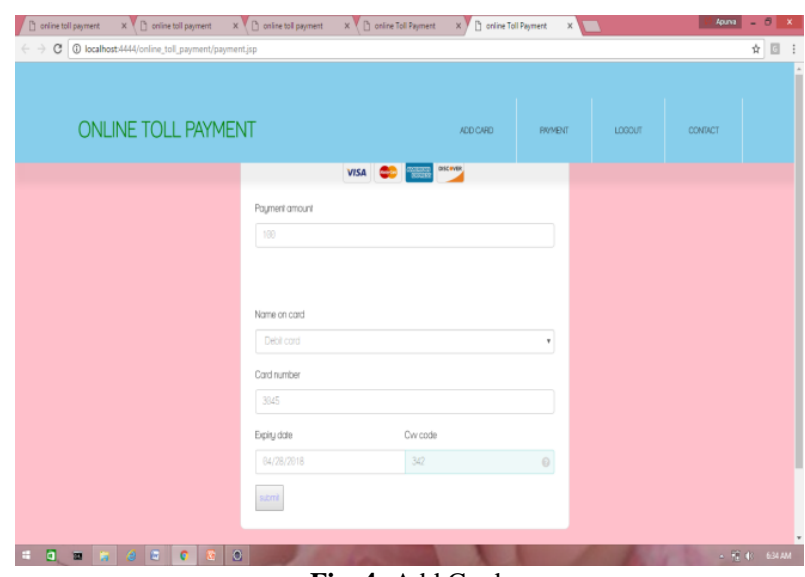

Fig. 4: Add Card.

Then select tollgate and paid fee of tollgate then generate receipt with barcode it's to the tollgate person verification of payment.

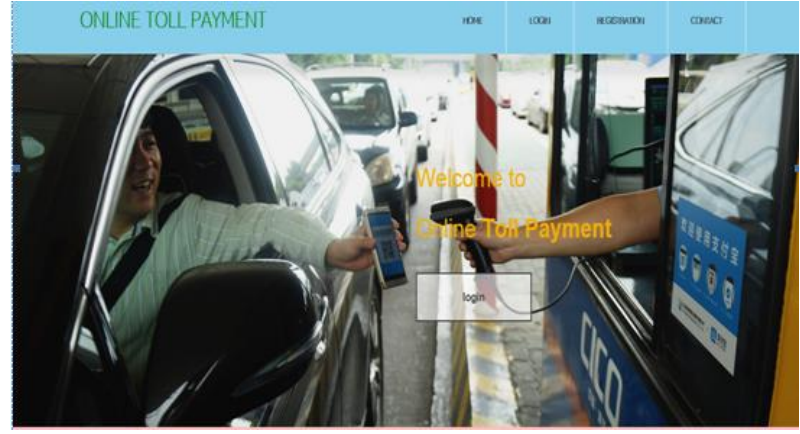

Fig. 3: Verification of Payment.

\section{Conclusion}

This paper depicts the reduce waiting of tollgate fee at tollgate and enhance the secure payment through online. Through this before reached to the tollgate you will pay the tollgate in login account based which type of payment type add to the account and after successful payment it will generate receipt with barcode .To show receipt to tollgate free verifier authority, they will verified by using barcode scanner and after successful scanning,your payment transferred tollgate. Use this application to reduce the waiting, traffic, perfect toll fee. Future enhancement is automation of bill verification at tollgate and tollgate fee paid at single time between source and destination places of all tollgates.

\section{References}

[1] Karnav Shah and Saahil Shah "Secure Examination System using Biometric and QR Code Techno logy" Volume.7 April 2017.

[2] Ranjani. S and Kalpana. K"online tollgate management system", Volume.2 March 2016.

[3] P Rithuja "Online Payment for Toll Gates" Volume.5 May 2014 G. Jones and E. Zeisler "Web-based messaging management using Java servlets" august 2002.

[4] Nielet D“mello and Larkins Carvalho "Struts 2- The modern web application framework" Volume.2 2013.

[5] M. Venkatesh"Design and implementation of vehicle tracking system using GPS, GMS and GPRSs mobile communication networks"Volume.7 September 2016.

[6] P. Ramesh and L. Chanra Shekar "Design and Implementation of Vehicle Tracking System Using GPS/GSM/GPRS Technology and Smart Phone A pplication"Volume.2 March 2015.

[7] Ch. Vinay Kumar and M. Rama Krishna" Design and implementation of real time vehicle tracking system Volume.4 July 2015.

[8] wikipedia.org/www.w3schools.com/javapoint. 